\title{
Palestina e categorias locais: diferenças entre usos terminológicos em produções
}

\section{bibliográficas e categorias palestinas locais}

\author{
Palestine and local categories: differences between terminological uses in biblio- \\ graphic productions and local Palestinian categories
}

Palestina y las categorías locales: diferencias entre los usos terminológicos en producciones bibliográficas y las categorías palestinas locales

\begin{abstract}
Resumo: A partir de trabalho de campo de dois anos, na Palestina, foi possível observar, em termos de usos locais de categorias espaciais, a existência de uma "Palestina única" - referência cartográfica composta pela soma de quatro espaços: Faixa de Gaza, Cisjordânia, Jerusalém e 48 (ou Al Dakhel "dentro", em árabe). Neste artigo, reflito sobre as produções bibliográficas acadêmicas brasileiras, especialmente antropológicas e de aporte etnográfico, que têm a Palestina como tema central mas que, de modo geral, não têm acesso às - e, portanto, não são informadas por - categorias palestinas locais. Esta defasagem termina por compor a construção e reprodução de um status quo categórico, pouco informado por expressões locais. Tais reflexões buscam trazer à luz as construções palestinas locais de espaços e identidades, enfatizando-as e, assim, contribuindo para uma aproximação das produções bibliográficas brasileiras sobre a região com as categorias palestinas locais.
\end{abstract}

Palavras-chave: Palestina, Territorialidades, História, Terminologias

\begin{abstract}
From a fieldwork of two years in Palestine, it was possible to observe, in terms of local uses of spatial categories, the existence of a "single Palestine" - a cartographic reference composed by the sum of four spaces: Gaza Strip, West Bank, Jerusalem and 48 (or Al Dakhel - Arabic for "inside"). In this article, I reflect on Brazilian academic bibliographic productions, especially anthropological and with ethnographic approaches, that have Palestine as a central theme but, in general, do not have access to - and therefore are not informed by - local Palestinian categories. This gap ends up composing the construction and reproduction of a categorical status quo, little informed by local expressions. Such reflections seek to highlight the Palestinian local constructions of spaces and identities, emphasizing them and, thus, contributing to an approximation of the Brazilian bibliographic productions about the region with the local Palestinian categories.
\end{abstract}

Keywords: Palestine, Territorialities, History, Terminologies

Resumen: A partir de dos años de trabajo de campo en Palestina, fue posible observar, en términos de usos locales de categorías espaciales, la existencia de una "única Palestina", una referencia cartográfica compuesta por la suma de cuatro espacios: la Franja de Gaza, Cisjordania, Jerusalén y 48 (o Al Dakhel - "interior", en árabe). En este artículo, reflexiono sobre las producciones bibliográficas académicas brasileñas, especialmente antropológicas y etnográficas, que tienen a Palestina como tema central pero que, en general, no tienen acceso a las categorías palestinas locales. Este vacío

1 Pós-Doutorando no Departamento de Letras Orientais (DLO) da Faculdade de Filosofia, Letras e Ciências Humanas (FFLCH) da USP. Pesquisador do integrante do NAPER (Núcleo de Antropologia da Política, do Estado e das Relações de Mercado), UFPR.

Copyright (C) 2021 autor. Este é um artigo em acesso aberto distribuído nos termos da Licença Creative Commons. Atribuição que permite o uso irrestrito, a distribuição e reprodução em qualquer meio desde que o artigo original seja devidamente citado.

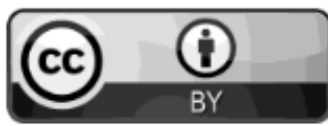


acaba componiendo la construcción y reproducción de un statu quo categórico, poco informado por las expresiones locales. Estas reflexiones buscan sacar a la luz las construcciones locales palestinas de espacios e identidades, enfatizándolas, y contribuyendo así a una aproximación de las producciones bibliográficas brasileñas sobre la región con las categorías locales palestinas.

Palabras clave: Palestina, Territorialidades, Historia, Terminologías

\section{Uma Palestina mais ampla: enunciando a questão ${ }^{2}$}

As reflexões apresentadas neste artigo decorrem da condução de trabalho de campo in loco, na Palestina, pelo período de dois anos. Com especial ênfase nas reflexões constituintes de minha tese doutoral, foi neste período, em campo, que passei a observar que tanto as construções locais de territorialidade quanto suas componentes identitárias são, seguramente, bastante mais fluidas, diversas e por vezes distintas do que habitualmente aparecem referenciadas em trabalhos bibliográficos em geral - principalmente naqueles produzidos fora da Palestina e, para este artigo, naqueles produzidos no Brasil.

Grosso modo, em acordo com categorias de territorialidade locais, a Palestina não se restringe à existência de dois espaços apenas, a saber, a Faixa de Gaza e a Cisjordânia - ou os TPO (Territórios Palestinos Ocupados). Muito além disto, a Palestina é composta localmente, em termos categóricos, por quatro espaços distintos, quais sejam os dois já citados, somados de Jerusalém e “48” (ou sua variante Al Dakhel - interno / dentro, em tradução livre do árabe). Para o caso das últimas - " 48 " e "dentro" - , estas são construídas enquanto categorias contrastivas em relação ao que busco chamar de seu par opositor, a saber, a categoria "Israel". Em outras palavras, busco colocar em contraste os termos "Israel" e "48" ("dentro"), quando tomados enquanto categorias locais de espaço. ${ }^{3}$ Assim, a referência cartográfica referida pela Comunidade Internacional como pertencente ao Estado de Israel - considerando-se as fronteiras de 1967 - é também referenciada, em acordo com as categorias palestinas locais, por seus pares opositores - “48” e "dentro". Contudo, estes usos terminológicos, ainda que claramente imperativos nas dinâmicas cotidianas na Palestina, não encontram eco em produções bibliográficas sobre o tema.

2 O presente trabalho é parte componente do previsto no projeto de pesquisa vinculado ao programa de pós-doutorado do DLO (Departamento de Letras Orientais), da FFLCH (Faculdade de Filosofia, Letras e Ciências Humanas) da USP. Também, os pensamentos aqui apresentados foram escritos a partir de reflexões presentes no item 8.1 do oitavo capitulo de minha tese de doutorado "Al Dakhel, cartografias como experiência: reflexões a partir de um trabalho de campo na Palestina” (OLIVEIRA, 2020).

3 Estas referências de espaço, contam com seu uso largamente observável no idioma árabe, com destaque para a categoria "dentro" (لخاد -Al-Dakhel) e sua variante, "dentro / interno ocupado" (لتحملا لخادلا - Al-Dakhel al muhttal). 


\section{Categorias espaciais locais}

A Palestina tem estado, há tempos, no centro de importantes debates, firmados em todo o globo, com importantes contribuições oferecidas pelas mais diversas áreas do conhecimento. As produções brasileiras sobre o tema são igualmente amplas e, certamente, bastante fundamentais para a constituição local de debates, divulgação e construção de conhecimentos específicos sobre a Palestina. No entanto, observa-se um certo "lugar-comum" terminológico, construído e acionado em obras bibliográficas - acadêmicas ou não - acerca não apenas da Palestina, mas do Oriente Médio de modo mais amplo. Desta forma, o que proponho chamar de binômio rígido terminológico, a saber, "Palestina versus Israel", termina por constituir o que entendo ser um status quo referencial nas produções bibliográficas que, por sua vez, terminam por responder mais às categorias dominantes (grosso modo, israelenses) do que palestinas. A proposição de reflexões sobre a constituição deste "lugar-comum" terminológico é parte do interesse deste artigo, assim como, principalmente, a busca por trazer à luz categorias palestinas de espaço e expressões identitárias, evidenciando seus usos contrastivos em relação às categorias israelenses.

Aqui, torna-se importante trazer o leitor ao contexto sob o qual tais categorias ganham sentido. Para tanto, faz-se necessário notar que o ano de 1948 é central, enquanto marcador temporal importante na construção de categorias de espaço e identitárias. Isto se deve ao fato de que foi neste ano que surge, em território palestino, o Estado de Israel. Tal surgimento se dá após a instauração prática de um plano de partilha, deliberado pela então recém-criada ONU (Organização das Nações Unidas). Após a recusa na adoção das proposições das comissões Peel e Woodhead - instauradas para a proposição cartográfica da partilha da Palestina - é aceita a resolução 181, datada de 29 de novembro de 1947. A implantação desta resolução, sobre a qual a população palestina jamais teve parte alguma (assim como jamais fora sequer consultada), levou ao surgimento do Estado de Israel em 15 de maio de 1948, data central, também, para a compreensão da chamada Nakbah, referida em língua portuguesa como "catástrofe" - em referência à expulsão da população palestina local e à instauração da nova conjuntura social e política que passara a acontecer no entorno da referida data em diante. Este evento é relembrado, na forma de celebrações, rituais e demais expressões, anualmente até os dias atuais. Neste sentido, a própria Nakbah pode ser apontada enquanto uma construção contínua e cotidiana, tanto nas referências locais à "tragédia contínua" e ininterrupta, quanto pela atualização constante do sentido terminológico temporal, que garante sentido às referências categóricas centrais neste 
trabalho. ${ }^{4}$ Dito de outro modo, este marcador temporal pode ser compreendido tanto enquanto constituinte do mito de origem da condição do refúgio palestino (SCHIOCCHET, 2011) como, na mesma via, das categorias aqui apresentadas - uma vez que este marcador informa os modos diversos de "ser palestino" no mundo, incluindo-se na própria Palestina. Estas categorias, contudo, são também construídas cotidianamente, no trânsito diário de sujeitos palestinos por / entre os diferentes espaços aqui referidos.

Observe-se, também, que naquele período, após a retirada das tropas do mandato britânico da Palestina, no dia 14 de maio de 1948, o recém-criado Estado israelense expande suas fronteiras para além daquelas instituídas no plano de partilha da resolução 181. Com isto, a partir da consolidação desta nova configuração cartográfica da região, é criada a chamada Linha Verde, separando o que viria a ser reconhecido como o espaço pertencente ao Estado de Israel e os chamados "territórios palestinos". O “interior" da Linha Verde, assim, é o que garante o sentido à categoria "dentro" (em árabe, Al Dakhel). Esta categoria conta com sua variante " 48 " - acima apresentada enquanto uma categoria de tempo que se constrói, também, enquanto categoria de espaço e identitária ("palestinos de 48", por exemplo, são aqueles sujeitos palestinos nascidos no "espaço 48"). De modo mais direto, estas categorias são acionadas em contraposição a seu par opositor, ou seja, em lugar de "Israel", aciona-se “48” ou “dentro". Em suma, pode-se observar em termos categóricos locais a construção e o acionamento cotidiano de quatro principais categorias palestinas de territorialidade, quais sejam, Faixa de Gaza, Cisjordânia, Jerusalém e 48 - ou sua variante terminológica "dentro", em árabe: $A l$ Dakhel $l^{5}$. Deste modo, "48" e "dentro" referem-se ao espaço da Palestina cuja comunidade internacional compreende enquanto pertencente ao Estado de Israel (ibid. p. 23).

A bibliografia que debate os eventos em torno do ano de 1948 é vasta e, também, se constrói em um embate entre as narrativas palestinas e a "história oficial" israelense. No entanto, importantes movimentos têm colocado à prova os fundamentos que constituem as versões israelenses sobre os eventos daquele período, trazendo à tona versões outras, evidenciando as perspectivas palestinas. Refiro-me às abordagens historiográficas que apontam para a expulsão dos palestinos da Palestina, a partir de 1948 versus narrativas israelenses que apontam para um "êxodo voluntário" da população palestina local considerando-se o mesmo período. Sobre isto, as próprias narrativas sionistas tornaram-se alvos centrais de processos revisionistas críticos, tal qual aponta Sheila Schvarzman (2013), ao afirmar que fatos e personagens históricos israelenses estão na base da grande revisão que vem

\footnotetext{
$4 \quad$ Para uma leitura mais aprofundada sobre a chamada "Nakbah contínua", consultar Zarefa Ali (2013).

5 Rafael Gustavo de Oliveira. Al Dakhel, cartografias como experiência: reflexões a partir de um trabalho de campo na Palestina. Tese (Doutorado em Antropologia), UFPR, Curitiba, 2020, p.22.
} 
sendo empreendida desde os anos 1980 pelo que se convencionou chamar novos historiadores póssionistas (SCHVARZMAN, 2013, p.136) ${ }^{6}$. Na mesma via, como aponta a historiadora Arlene Clemesha (2009), certos mitos fundadores do Estado de Israel, como aquele dos "poucos contra muitos" (sua suposta fragilidade perante um mundo árabe determinado a erradicá-lo em 1948) e "egresso voluntário dos árabes", foram irremediável e definitivamente abalados por avanços concluídos pela historiografia israelense e palestina (CLEMESHA, 2009, p.11) ${ }^{7}$. No entanto, ainda que sejam notórios tais avanços, compartilho minha inquietação com a carência de evidência das categorias e terminologias palestinas locais em produções bibliográficas sobre o tema - ainda que sejam, também, componentes próprias das produções historiográficas aqui referidas.

Algumas referências pontuais apresentam tais termos, ainda que de forma rápida, tal qual Edward Said (1999) ao afirmar que; the phrase min al-dakhil, 'from the interior', has a special resonace to the Palestinian era. It refers, first of all, to regions of the interior of Israel, to territories and people still Palestinian despite the interdictions of the Israeli presence. (SAID, 1999, p.51). ${ }^{8}$ Entretanto, estas categorias palestinas não encontram eco considerável nas produções bibliográficas em geral, ainda que sejam parte constituinte importante do cotidiano local, amplamente percebidas com estadias in loco. De minha parte, as observações acerca da construção e usos cotidianos locais de expressões identitárias e suas equivalentes espaciais tiveram início em minha primeira estadia em campo, no ano de 2014. Em uma conversa com um músico local, este me perguntara se eu estaria, também, trabalhando com "músicos de 48". De pronto, julguei tratar-se de sujeitos eventualmente nascidos neste ano, ou que, de certa forma, comporiam produções musicais relacionadas à data. No entanto, tão logo a conversa evoluíra, pude notar que o acionamento da categoria “ 48 ” estava explicitamente relacionado à referências espaciais. Ao comentar sobre a proveniência de sua família deste espaço, mais especificamente da cidade de Haifa, ficara evidente o aspecto contrastivo do termo com relação ao seu par opositor, "Israel”. Para o músico, aquele espaço é a Palestina tanto quanto a Cisjordânia, Faixa de Gaza e Jerusalém.

Contudo, foi a partir de meu retorno à Palestina, para a pesquisa de campo de meu doutoramento e, no concomitante exercício da docência de música em instituições palestinas, que pude me debruçar mais sobre tais reflexões. A observação do fluxo cotidiano de sujeitos palestinos por / entre

6 Sheila Schvarzman. "Israel: Nova história e cinema pós-sionista". Significação: Revista de Cultura Audiovisual 40, 40 (2013).

7 Arlene Elizabeth Clemesha. Da ideia de transferência à realização da limpeza étnica: contribuições da nova historiografia israelense e palestina. PUCVIVA 34, Janeiro/Abril, 2009.

8 Edward W. Said. After the Last Sky: Palestinian Lives. Columbia University Press, New York, 1999. 
diferentes espaços (principalmente entre 48, Jerusalém e Cisjordânia) se tornara componente importante de meu cotidiano. Também, foi a partir de minha estadia sem visto por aproximadamente seis meses - até que a situação fosse regularizada pelas autoridades israelenses competentes - , que pude observar e compor a construção e práticas de estratégias de mobilidade entre os referidos espaços. A partir da impossibilidade de trânsito em função da falta de documento permissivo ${ }^{9}$, compus e presenciei arranjos de alunos para a realização de aulas, ensaios e apresentações. Isto se deve à diferença na possibilidade de trânsito entre palestinos de diferentes espaços. Grosso modo, o "palestinos de 48" (ou, palestinos “de dentro"), assim como os "palestinos de Jerusalém”, têm livre acesso à Cisjordânia. Já os palestinos green id (da Cisjordânia e Faixa de Gaza) dependem da expedição de documentos permissivos por parte das autoridades israelenses, comumente negados. ${ }^{10}$ Assim, é notoriamente comum que, na impossibilidade de trânsito de uns, organizem-se, na Cisjordânia, as agremiações a partir da possibilidade de trânsito de outros.

Com isso, tal qual demonstro em minha tese de doutorado, ainda que considerados os percalços e as im/possibilidades de mobilidade (uma vez que há, de modo geral, a necessidade do porte de documentos permissivos para o cruzamento de checkpoints $^{11}$ ), o trânsito diário de palestinos por diferentes espaços termina por constituir a construção de um "mapa alternativo" (MONTENEGRO, 2007), a saber, o da "Palestina toda", composto pelos quatro espaços distintos - Faixa de Gaza, 48, Jerusalém e Cisjordânia.

\section{Reflexões sobre produções bibliográficas}

A forma como tais categorias são acionadas cotidianamente dificilmente são referidas e encontradas em produções bibliográficas, com especial destaque para aquelas produzidas fora da Palestina. Esta observação pode apontar para uma certa restrição do acesso ao conhecimento da própria existência de tais categorias, o que informa, de certo modo, a construção e reprodução do referido binômio rígido - imprimindo nos espaços e nos sujeitos palestinos categorias estanques que, por sua vez, não competem com a diversidade e fluidez de seus usos contextuais locais, como observado

\footnotetext{
9 Nesta referida circunstância meu visto havia expirado e o processo para regularização de minha estadia durou alguns meses. Ao final, terminei por contar com dois vistos, com extensão de um ano cada.

10 As referências às proveniências dos sujeitos também acontecem a partir da distinção de cores entre os documentos. Palestinos da Faixa de Gaza e da Cisjordânia contam com documentos verdes, ao passo que palestinos com documentos israelenses (de 48) possuem documentos azuis e, assim, são referidos como blue ids. Palestinos de Jerusalém possuem documento próprio, também de cor azul, contudo, são referidos pela localidade mais do que pela coloração, a exemplo de jerusalemite ou "de Jerusalém".

11 Postos militares israelenses de controle de trânsito de sujeitos.
} 
localmente. Desta forma, o próprio exercício de tornar centrais as categorias palestinas na confecção de produções bibliográficas pode, de certa maneira, alocar pesquisadores que as evidenciem em uma espécie de "contramão da regra" (OLIVEIRA, 2020) dos usos terminológicos - usos estes que, uma vez dominantes, são acionados visando a consolidação de uma pretensa neutralidade que, neste sentido, não é nada neutra. Esta observação, contudo, urge de aprofundamento.

A organização BADIL (Resource Center for Palestinian Residency \& Refugee Rights), de Belém, publicou, no ano de 2012, um trabalho intitulado "One People United: A Deterritorialized Palestinian Identity". Nesta publicação, a organização apresenta o resultado de uma série de perguntas realizadas a palestinos em todos os espaços aqui referidos, em que aponta a predominância absoluta da identificação enquanto "palestinos" independente do espaço em que a enquete fora realizada. Assim, categorias como "palestino" ou "palestino com documentos israelenses", por exemplo, se sobressaem de forma absoluta, em relação às outras possibilidades apresentadas na pesquisa da organização aos entrevistados, como "israelense”, “árabe-israelense”, entre outras (no caso dos palestinos de 48). Contudo, ainda que apresentando a predominância das categorias identitárias, o texto conta com uma justificativa do uso terminológico das expressões de territorialidade (desconsiderando "dentro" e " 48 " como possibilidades, ainda que esta última seja referenciada). Segue o trecho:

\begin{abstract}
Due to the existing multiplicity of naming related to Palestinian citizens of Israel (Israeli Arabs; 1948 Palestinians; the Inside [the Green Line] Palestinians and so forth), each title carries political and ideological components. Throughout this paper we will refer to the indigenous community in Israel as 'Palestinian citizens of Israel'. This term is accepted academically to be 'neutral'. Our analytical use of the term is irrespective to self-identifications of respondents to our survey. (BADIL, 2012, p.11, 12) ${ }^{12}$. Grifo meu.
\end{abstract}

Assim, ainda que o trecho justifique a busca por uma "neutralidade acadêmica", pode-se observar que "Israel”, aqui tomado enquanto uma categoria de espaço, prevalece sobre outras possíveis, reificando as terminologias dominantes (as israelenses). Esta busca por uma pretensa neutralidade, note-se, acomete parte considerável das publicações sobre o tema. De modo geral, alguns autores parecem essencializar os diferentes espaços, de modo a pensar o binômio "Palestina versus Israel" como algo um tanto "dado", sem considerar categorias nativas de territorialidade e a maneira como operam $^{13}$.

12 Badil. One People United: A Deterritorialized Palestinian Identity. In: BADIL's Working Paper No. 14. BADIL Survey of Palestinian Youth on Identity and Social Ties, Resource Center for Palestinian Residency \& Refugee Rights, Bethlehem, Palestine, 2012.

13 Rafael Gustavo de Oliveira. Al Dakhel, cartografias como experiência : reflexões a partir de um trabalho de campo na Palestina. Tese (Doutorado em Antropologia), UFPR, Curitiba, 2020. p. 236. 
Entretanto, é importante sublinhar que trazer tais apontamentos não é negar a existência e uso cotidiano do referido binômio (acionado, também, de forma contextual tanto por palestinos como por israelenses), mas sim, destacar a percepção de que este parece ser, muitas vezes, dotado de uma rigidez tal que sua problematização é quase imperceptível, se tornando, assim, uma espécie de "tabu intocável" (ibid). Dito de outro modo, pode-se observar uma certa carência de coesão terminológica nas citações à Palestina, no que diz respeito às espacialidades locais (como o proposto neste artigo) muitas vezes referida por reduções generalistas como "Territórios Palestinos", "Territórios Ocupados", "Cisjordânia e Faixa de Gaza" (ou, por vezes, apenas "Gaza"). O mesmo não ocorre no acionamento da categoria "Israel”, sendo garantido a esta uma certa imutabilidade, um "óbvio inquestionável". Também, neste sentido, uma certa predileção da categoria "israelense" é notoriamente presente em produções diversas, no que diz respeito às terminologias referenciais identitárias.

Importante ressaltar que esta disputa semântica não ocorre de forma unilateral, uma vez que, de acordo com categorias locais israelenses, espaços para além das delimitações cartográficas apontadas nas “fronteiras de 1967”, são também “componentes de Israel”. A Cisjordânia, por exemplo, é referida de forma recorrente como "Judeia e Samaria", termo usado, inclusive, na confecção de documentos emitidos por autoridades competentes, tal qual um carimbo que tive em meu passaporte, em um visto específico que restringia minha permanência à Cisjordânia por um ano. Neste, a inscrição "Judea and Samaria only permit" é observada. Esta modalidade de visto, em acordo com as expressões locais palestinas, é comumente referida como "West Bank only visa". Estas categorias israelenses, tais quais seus pares opositores palestinos, tampouco aparecem nas produções bibliográficas sobre as quais reflito. Contudo, torna-se importante notar que fazer tal afirmação não é desconsiderar que a predominância do binômio rígido "Palestina versus Israel" não seja por si só, a meu ver, um status quo terminológico informado mais por imperativos categóricos israelenses. Assim, mesmo que as categorias locais não sejam evidenciadas (sejam palestinas ou mesmo israelenses), a reprodução das terminologias rígidas dominantes termina por ofuscar as expressões palestinas locais - ainda que de modo nada intencional.

Tais observações se tornaram explícitas tão logo passei a debruçar-me sobre o levantamento de publicações acerca de práticas e produções musicais palestinas - tema de minha dissertação de Mestrado $^{14}$. Como exemplo, o trabalho My Voice Is My Weapon: Music Nationalism and the Poetics of Palestinian Resistence, de David A. McDonald (2013) traz em seu capítulo New Directions and

14 Selah al Museka: uma etnografia das práticas e produções musicais palestinas. Dissertação de Mestrado, UFPR, Curitiba, 2015. 
New Modalities: Palestinian Hip-Hop in Israel o termo Palestinian Israeli com evidente recorrência. Na mesma via, em uma produção de tema similar de título Playing Across a Divide: Israeli- Palestinian Musical Encounters, publicada por Benjamin Brinner (2009), nota-se a referência a palestinos através de expressões como arabs in Israel and the West Bank, no capítulo de mesmo nome. Também sobre música, Karin Heim (2011) publica Beats Not Bombs: Hip-Hop To Create Peace In The IsraeliPalestinian Conflict, apresentando a predominância da categoria Arab-Israeli. Da mesma forma, ainda tendo o rap como objeto de reflexão, Hugh Lovatt (2009), em Palestinian Hip-Hop Culture and Rap Music: Cultural Resistence as an Alternative to Armed Struggle, assim como os demais autores, fez seu campo in loco e, fazendo referências de espaço, afirma que conduziu sua pesquisa: "[...] in Israel and the Palestinian West Bank during January 2009"15. Neste trabalho, ainda que o autor acione a categoria "Palestina", esta não é assumida enquanto uma referência de territorialidade (de forma a responder aos imperativos locais), diferente do uso que Lovatt faz da categoria "Israel", que aparece dada e estanque. Assim, sobre os usos políticos das produções palestinas de rap, estes deveriam, em suas palavras [...] deliver not only a lasting peace settlement but also improvements in basic living conditions for Palestinians in both the Occupied Territories and Israel proper (ibid, p.13). Grifo meu.

Ainda acerca das produções sobre música, Mark Levine (2008), em seu livro Heavy Metal Islam: Rock, Resistance And The Struggle For The Soul Of Islam o autor apresenta um capítulo intitulado Israel / Palestine: Hard Music in an Orphaned Land, onde explica o uso de categorias identitárias para a referência aos sujeitos com quem desenvolvera sua pesquisa. Segundo o autor: I use "Palestinian Israelis" to refer to Palestinian citizens of Israel, and "Palestinians" to refer to Palestinians living in the West Bank, Gaza and the Diaspora ${ }^{16}$.

Sobre os autores aqui apresentados, observo que seus trabalhos foram redigidos a partir de suas experiências de campo, in loco. Com isso, destaco uma inquietação que em certo grau me acomete, a saber, se os autores optam de forma deliberada pelos usos de tais categorias, ou se respondem aos imperativos categóricos expressos por seus interlocutores - uma vez que, compondo e observando o trânsito entre diferentes espaços e tendo como interlocutores palestinos de diferentes localidades, é bastante provável que tenham tido acesso às categorias de expressões identitárias e de territorialidades que aqui destaco ("48" e "dentro", por exemplo). Contudo, de modo geral, ainda que a proximidade dos trabalhos com interlocutores palestinos seja evidente, percebe-se a existência de certa cautela nos

15 Hugh Lovatt. Palestinian Hip-Hop Culture and Rap Music: Cultural Resistance as an Alternative to Armed Struggle. BA Arabic. Institute of Arabic and Islamic Studies, Exeter University, 2009. p. 6.

16 Mark Levine: Heavy Metal Islam: Rock, Resistence, And The Struggle For The Soul Of Islam. Three Rivers Press, New York, 2008. p. 106. 
usos terminológicos de referência à Palestina, ao passo que, quando relacionado às categorias israelenses, parece imperar uma certa naturalidade, um "lugar comum" indiscutível. Dito de outro modo, reitero que enquanto "Israel é óbvio", a "Palestina não é tanto"17.

A busca pela resolução das inquietudes acerca dos usos terminológicos, assim, parece ser compartilhada entre pesquisadores do tema de modo amplo - não apenas relacionados a música, como os aqui destacados. Entretanto, a reificação das categorias israelenses e a alocação destas no campo de uma pretensa "neutralidade" contribuem, a meu ver, para a consolidação da obviedade "Israel", também enquanto componente da terminologia dominante. Ao mesmo tempo, constituem as dificuldades e indisposições em construir "Palestina" enquanto espaço "dado" (tal qual sua equivalência identitária), de forma a responder aos imperativos identitários e de territorialidade locais. Nestes termos, a "Palestina toda" (composta pela soma de quatro espaços distintos) não apenas existe localmente de forma notoriamente imperativa, como é observada a sobreposição cotidiana ao binômio rígido "Palestina versus Israel".

Os usos relacionados ao status quo terminológico, também, podem ser observados em publicações cuja pesquisa e trabalho de campo foram realizados em lugares outros que não na Palestina, a exemplo da vasta e importante bibliografia que tem a diáspora, o exílio, o refúgio e demais fluxos transnacionais de sujeitos palestinos ao redor do globo. Trazer tal reflexão à luz não é, de nenhuma maneira, apontar críticas de cunho negativo a estas produções, cuja qualidade técnica e importância acadêmica e científica é indiscutivelmente evidente. Mas é, sim, afirmar que, muitas das vezes, estas produções terminam por lançar mão das terminologias "dadas", se colocando, assim, como partes compostas e componentes da construção das referências dominantes (ibid). Tal qual proposto por Leonardo Schiocchet (2015) ao fazer a proposição de uma "antropologia assimétrica da palestinidade", a neutralidade acadêmica, quando relacionada a trabalhos que têm a Palestina em seu cerne, não é neutra. Nesta via, tenho buscado refletir sobre como a manutenção e acionamento, ainda que de forma não intencional, da busca por esta posição "neutra" pode reificar a constituição do status quo terminológico, informado de forma imperativa mais por categorias israelenses do que por categorias locais palestinas.

Isto posto, pode-se observar que boa parte da bibliografia brasileira sobre a Palestina conta com a reprodução dos mesmos amparos terminológicos. Tal como sugeri acima, dizer isto não é minimizar a notável qualidade dos trabalhos produzidos no Brasil, mas é, em outra via, buscar refletir

17 Rafael Gustavo de Oliveira. Al Dakhel, cartografias como experiência: reflexões a partir de um trabalho de campo na Palestina. Tese (Doutorado em Antropologia), UFPR, Curitiba, 2020. p. 237. 
sobre a possível falta de acesso que pesquisadores têm às categorias palestinas locais. No campo da antropologia brasileira que tem a Palestina como interesse - lugar acadêmico de onde eu também advenho -, embora diversas publicações já tenham se consolidado com inegável importância, a carência de trabalhos de campo in loco, por períodos mais extensos é, também, bastante notória.

Levando-se em especial consideração a produção bibliográfica antropológica, tem-se a percepção de uma considerável predominância de trabalhos relacionados à diáspora, refúgio e demais fluxos migratórios - redigidos por pesquisadores brasileiros e majoritariamente produzidos a partir de instituições brasileiras. Vale sublinhar, no entanto, que a escolha por temas relacionados a palestinos está longe de ser exclusividade da antropologia, figurando em produções das mais variadas áreas do conhecimento - tenham estas amparo etnográfico ou não. Contudo, torna-se importante notar que a proximidade com comunidades palestinas fora da Palestina e, neste caso, em especial aquelas presentes no Brasil e América Latina em geral, é parte importante da constituição dos trabalhos desenvolvidos com ênfase em abordagens etnográficas. Entretanto, frise-se, estas não são a única via de pesquisa possível, uma vez que importantes trabalhos fundados em levantamentos bibliográficos (e outras abordagens metodológicas) são, também, importante parte constituinte da vasta produção brasileira sobre o tema - Palestina e palestinos.

Isto posto, e mais uma vez enfatizando as publicações mais próximas à minha trajetória enquanto pesquisador em antropologia, algumas referências podem ser notadas - dentre as várias possíveis, de disciplinas diversas. Tendo palestinos no extremo sul do país como objeto de pesquisa, Denise Jardim $(2000,2002$, 2015) apresenta seus trabalhos a partir de campo realizado no Chuí, Rio Grande do Sul, firmando-a como uma das precursoras nas produções de amparo etnográfico sobre o tema na antropologia brasileira. Nesta mesma via, destaco as produções de Sônia Hamid (2012, 2013, 2015) e Daniele Abilas Prates (2012, 2015), acerca dos processos de reassentamento de palestinos no Brasil e, respectivamente, sobre a construção de redes locais e transnacionais das mesmas comunidades. Também de cunho etnográfico, em aproximação com temas como refúgio, destaco Helena Manfrinato (2017). Outras produções, mesmo que não sempre amparadas por perspectivas etnográficas, podem também ser notadas, a exemplo das recentes publicações de Hissa Mussa Hazin (2016), Hanin Dawud (2020), Cláudia Stephan (2012, 2014, 2018), Luciana Garcia de Oliveira (2017), Zenilda Lopes Ribeiro (2019), Renatho Costa (2020), Fernando Antônio Resende (2014, 2015), Geraldo Adriano Godoy de Campos (2019), Luciano Kneip Zucchi (2020), Sheila Schvarzman (2013). É notável, também, a vasta produção da historiadora Arlene Clemesha (2006, 2008, 2009, 2020). Ainda, vinculados à instituições brasileiras, pode-se destacar pesquisas realizadas em outros países latino-americanos, a 
exemplo das produções de Cecília Baeza $(2005,2012,2014,2015,2017)$ e, mais recentes, as desenvolvidas no Chile por Bárbara Caramuru Teles (2017, 2020, 2020).

Também, a partir de pesquisas realizadas em países do Oriente Médio, alguns trabalhos urgem ser notados, a exemplo de publicações acerca das comunidades de refugiados palestinos no Líbano como em Gustavo Barbosa (2015), Gisele Chagas e Paulo Hilu (2013), Amanda Dias (2015) e Leonardo Schiocchet $(2011,2012,2013,2014,2015,2017)$. Ainda com relação às pesquisas realizadas no Oriente Médio, podem ser destacadas as conduzidas na Palestina, com presenças mais ou menos extensas em campo, a exemplo de Danilo Guiral Bassi $(2016,2020)$ e, novamente, Daniele Abilas Prates (2012). Sobre Prates, a proximidade firmada com a pesquisadora passara a ser componente de minha própria experiência de campo, uma vez que sua extensa estadia in loco fora de notável importância para minha inserção em determinadas redes locais, em 2014. Por fim, nesta mesma via, considero também os meus próprios trabalhos, confeccionados a partir de minha estadia de campo.

Importante notar, no entanto, que os trabalhos aqui citados estão longe de ser os únicos componentes da produção bibliográfica sobre o tema, produzida no Brasil ou por pesquisadores brasileiros. ${ }^{18}$ Apontar, de forma mais criteriosa, a vasta produção nacional sobre o tema demandaria um número considerável de páginas. Contudo, evidencia-se um ponto mais ou menos comum entre a maior parte das referências aqui apresentadas, a saber, a escassez de trabalho de campo, na Palestina, por períodos mais extensos ou, na existência destas estadias, estas não se mostram satisfatoriamente evidenciadas. Aqui, note-se com especial atenção, me refiro à produções cuja pesquisa faz referência direta às dinâmicas palestinas locais e não àquelas que têm a diáspora, deslocamentos e demais fluxos de sujeitos palestinos como tema. Ressaltar tal observação não descredita os importantes trabalhos realizados em outras localidades - fora da Palestina -, nem tampouco seus extensos e bastante relevantes trabalhos de campo em outros países, mas sim, coloca em perspectiva a pluralidade de categorias que respondem aos imperativos locais específicos. Dito de outra forma, a exemplo de expressões como as identitárias e de territorialidade, componentes de tais produções, estas nem sempre respondem àquelas observadas no cotidiano local da Palestina. No entanto, como tenho afirmado, observa-se um certo consenso nos usos de tais terminologias, que respondem mais a um lugar-comum “dominante", quando o assunto das publicações volta-se à Palestina. Assim, reforço, a falta de uma presença mais prolongada em campo, ou onde a inserção de pesquisadores nas dinâmicas cotidianas locais se faça evidente, pode estar informando a construção e reificação do que referi aqui como status

18 Uma busca mais dedicada por produções diversas é parte central da proposta de minha pesquisa de pós-doutorado, em curso no momento em que redigo este artigo. 
quo terminológico - recorrente em grande parte produções, especialmente, reitero, quando há apontamentos aos contextos palestinos locais (sejam estes em referência à Faixa de Gaza, 48, Jerusalém ou Cisjordânia).

\section{Centralidade do aporte etnográfico e as dificuldades na pesquisa in loco}

Como apontei anteriormente, durante minha estadia em campo trabalhei junto ao quadro docente do Conservatório Nacional Edward Said (ESNCM - Edward Said National Conservatory of Music), ministrando aulas de violão clássico na sede de Jerusalém. Neste período residi na cidade de Ramallah, na Cisjordânia, tendo o trânsito entre estes diferentes espaços como um importante componente cotidiano. Ainda, enquanto professor de música em outro conservatório, o Al Kamandjati, ministrei aulas (pelo mesmo período) na sede de Ramallah e na filial da cidade de Jenin, ao norte da Cisjordânia. Sobre isto, para além da composição e observação de trânsito cotidiano de palestinos entre diferentes espaços (em especial com relação ao deslocamento à / de 48 e Jerusalém), deslocamentos na própria Cisjordânia também se tornaram igualmente presentes - proporcionando a observação do trânsito de palestinos e, também, de colonos israelenses, a partir da proximidade com assentamentos.

Isto posto, observo que foi, justamente, a possibilidade da experiência cotidiana na Palestina, por um período mais prolongado, que possibilitou não apenas a observação mas, também, a composição das dinâmicas locais de trânsito e mobilidade por / entre diferentes espaços. Este trânsito cotidiano é componente central na construção dos referidos mapas alternativos, através da construção diária de uma cartografia experiencial, capaz de dissolver as delimitações cartográficas rígidas, dando lugar à construção de espaços outros - neste caso, de uma "Palestina única". Desta forma, advogando em favor da prática etnográfica, entendo que esta abordagem nas conduções de pesquisas pode ser de suma importância na construção de conhecimentos outros, mais informados pelas vivências diárias dos sujeitos da pesquisa em questão.

Pedra de toque do fazer antropológico, a etnografia é, com frequência, referenciada como ferramenta metodológica fundamental da disciplina. Vale notar, também, que reflexões sobre práticas etnográficas e seus desdobramentos são, há tempos, trazidas à luz nas discussões antropológicas - em função das realidades amplamente plurais em que as etnografias se fundam e, também, a partir das quais se constroem. Contudo, tal qual aponta Mauro de Almeida (2003), embora práticas etnográficas sigam sendo fundamentais para a própria prática antropológica, também há tempos esta deixou de ser 
metodologia exclusiva da referida disciplina. Trazer tal reflexão pode, inicialmente, denotar uma certa contraposição, já que com evidente constância as práticas antropológicas se (con)fundem com as etnográficas. Entretanto, reforço a perspectiva de que não apenas a etnografia há tempos deixou de ser exclusividade da antropologia, como tampouco a própria disciplina antropológica se vale unicamente deste recurso metodológico para a condução de suas pesquisas e reflexões.

Contudo, como proponho nas reflexões deste trabalho, foi a própria aproximação da condução da pesquisa com um trabalho etnográfico que possibilitou o alcance à observações de categorias que, de modo geral, não se evidenciam nos trabalhos bibliográficos sobre a Palestina. Entretanto, há que se ter o cuidado de não dotar os pesquisadores da responsabilidade sobre a carência do acesso às categorias palestinas locais, uma vez que a condução de trabalho de campo in loco encontra, com notável frequência, percalços e dificuldades das mais diversas.

A falta de fomentos, as barreiras idiomáticas, a evidente dificuldade enfrentada na aquisição e renovação de vistos israelenses e, por conseguinte, a própria manutenção da estadia e condução do campo figuram entre os pontos que impossibilitam a abordagem etnográfica presencial. Além disso, devem-se considerar com especial atenção as dificuldades e entraves encontrados em campo, levando-se em conta situações como intervenções e incursões do exército israelense, confrontos entre forças militares e a população local, manifestações diversas, constante falta de energia elétrica, greves gerais frequentes e demais situações adversas, comumente eclodidas de forma abrupta.

Esta instabilidade específica do campo na Palestina é ponto notório, tal qual descreve Majdi Al-Malki ${ }^{19}$. Entretanto, a busca pela exposição e evidência das práticas de trabalho de campo nas pesquisas in loco sobre Palestina, quando existirem, devem ser trazidas à luz.

\section{Apontamentos finais}

Acionamentos e usos de expressões locais de territorialidade e suas equivalências identitárias são imperativos importantes na pesquisa desenvolvida in loco. Trazer estas expressões, neste sentido, pode contribuir para o aprofundamento das reflexões e discussões sobre Palestina e, também, contribuir para trazer à luz as formas palestinas locais de construção cotidiana de espaços e identidades, enfatizando-as - em detrimento dos usos e da reificação de terminologias dominantes. Nesta perspec- 
tiva, produções brasileiras que tenham a Palestina como tema central passariam a estar mais informadas pelas categorias palestinas locais do que pelas terminologias do Norte global ${ }^{20}$ - em geral, relacionadas com o referido binômio rígido e fortemente informadas por terminologias israelenses. Realizar reflexões acerca das produções sobre o tema pode contribuir para o apontamento da reprodução do status quo terminológico, ao passo que proporcionaria direcionamentos mais condizentes com as expressões palestinas locais, de modo a responder menos aos imperativos dominantes. Trazer as dinâmicas locais da Palestina ao centro do debate, assim, se torna ponto de central importância, dada a carência de trabalhos de campo in loco na condução de trabalhos sobre a Palestina a partir do Brasil.

\section{Referências bibliográficas}

Al-malki, Majdi. Researching in an Unsuitable Environment: The Palestinian Case. In: Critical Research In The Social Sciences: A Transdisciplinary East-West Handbook. Published by the Ibrahim Abu-Lughod Institute of International Studies. Birzeit University and the Institute for Social Anthropology Austrian Academy of Sciences. Birzeit University, 2011.

Ali, Zarefa. A Narration Without an End: Palestine and the Continuing Nakba. The Ibrahim AbuLughod Institute of International Studies, Birzeit University, 2013.

Almeida, Mauro W. Barbosa. "Relativismo antropológico e objetividade etnográfica". Em: Campos - Revista de Antropologia, n3: 9- 29, UFPR, Curitiba, 2003.

BADIL. One People United: A Deterritorialized Palestinian Identity. In: BADIL's Working Paper No. 14. BADIL Survey of Palestinian Youth on Identity and Social Ties, Resource Center for Palestinian Residency \& Refugee Rights, Bethlehem, Palestine, 2012.

Baeza, Cecília. Les Palestiniens du Chili: de la conscience diasporique à la mobilisation transnationale. Revue d'Etudes Palestiniennes. v.95, 2005.

2012.

América Latina y la Cuestión Palestina (1947-2012). Araucaria (Madrid). v.14,

Palestinians in Latin America: Journal of Palestine Studies, v.43, 2014.

O "Refúgio" e o "Retorno" entre os Palestinos do Chile: Narrativa Identitária e Discurso Militante. Em: SCHIOCCHET, Leonardo (Org.). Entre o Velho e o Novo Mundo: A Diáspora Palestina Desde o Oriente Médio à América Latina. 1a edição. Chiado Print, Lisboa, Portugal, Julho, 2015.

Introduction: Journal of Palestine Studies, v.46, 2017.

Barbosa, Gustavo. Populações Imaginadas - Estatística e Não-Estado em Chatila, Líbano. Em: Entre o Velho e o Novo Mundo: a Diáspora Palestina Desde o Oriente Médio à América Latina. Chiado Editora, 1a edição: Julho, 2015.

20 Arlene Clemesha, Silvia Ferabolli. Studying the Middle East from Brazil: reflections on a different worldview. EI - Estudos Internacionais. 8, 4 (2020): 97-109. 
Brinner, Benjamin. Playing across a divide: Israeli Palestinian musical encounters, Oxford University, Press on Demand, 2009.

Campos, Geraldo Adriano Godoy de. Por uma filosofia da espera e da permanência: o tempo no cinema de Elia Suleiman e Kamal Aljafari. Tese de Doutorado. USP, São Paulo, 2019.

Chagas, Gisele F.; Pinto, P.G.H. Apresentação. Dossiê Exílios: etnografias de campos de refugiados palestinos no Líbano. Antropolítica: Revista Contemporânea de Antropologia, v. 35, p. 13-16, 2013.

Clemesha, Arlene Elizabeth. Uma educação para presevervar a identidade. Biblioteca Entre Livros, São Paulo, p. 36 - 41, 01 mar. 2006.

. Palestina, 1948-2008 - 60 Anos de Desenraizamento e Desapropriação. Forum, Universidade de São Paulo. Departamento de Letras Orientais. Ano V, 2008.

. Da ideia de transferência à realização da limpeza étnica: contribuições da nova historiografia israelense e palestina. PUCVIVA 34, Janeiro/Abril, 2009.

; Ferabolli, Silvia. Studying the Middle East from Brazil: reflections on a different worldview. Em: EI - Estudos Internacionais. v. 8, n. 4, p. 97-109, Belo Horizonte, 2020.

Costa, Renatho. O dilema da integração a partir da perspectiva do mercado de trabalho para os árabesisraelenses no estado de Israel. Em: Adi, Ashjan Sadique; Sahd, Fábio Bacila. (Orgs.) Oriente Médio e Palestina pesquisados a partir do Brasil: reflexões acadêmicas, marginais e críticas. Uberlândia: Navegando Publicações, 2020.

Dias, Amanda. Pintores de Beddawi: Entre Criação Artística e Engajamento Político. Em: Entre o Velho e o Novo Mundo: a Diáspora Palestina Desde o Oriente Médio à América Latina. Chiado Editora, 1a edição: Julho, 2015.

Dawud, Hanin M. W. M. K. A Missão Olímpica Rio 2016: locutores palestinos em questão. Dissertação de Mestrado. UFPR, Curitiba, 2020.

Guiral Bassi, Danilo. A ideia de um Estado binacional na Palestina histórica: conceitos, evolução histórica e perspectivas na atualidade. Dissertação de Mestrado, Faculdade de Filosofia, Letras e Ciências Humanas, Universidade de São Paulo, São Paulo, 2016.

Hamid, Sônia Cristina. (Des)Integrando Refugiados: Os Processos do Reassentamento de Palestinos no Brasil. Tese de Doutorado. UnB, Brasília, 2012.

. O reassentamento de palestinos no Brasil: discursos orientalistas de gênero. Seminário Internacional Fazendo Gênero 10 (anais eletrônicos), Florianópolis, 2013.

Árabes Estabelecidos e Refugiados Palestinos Recém- Chegados ao Brasil: tensões referentes ao "direito do retorno" e a uma "pedagogia de ascensão social". Em: Schiocchet, Leonardo (Org.). Entre o Velho eu Novo Mundo: A Diáspora Palestina Desde o Oriente Médio à América Latina. 1 a edição. Chiado Print, Lisboa, Portugal, Julho, 2015. 
Hazin, Hissa Mussa. Imigrantes palestinos, identidades brasileiras: compreendendo a identidade palestina e as suas transformações. Dissertação de Mestrado. UFPE, Recife, Pernambuco, 2016. Heim, Karin. Beats Not Bombs: Hip-Hop To Create Peace In the Israeli-Palestinian Conflict. Nota Bene: Canadian Undergraduate Journal of Musicology: Vol.4: Iss. 2, Article 5, 2011.

Jardim, Denise Fagundes. Palestinos no Extremo Sul do Brasil: Identidade e os Mecanismos Sociais de Produção de Etnicidade - Chuí / RS. Tese de Doutorado. UFRJ / PPGAS / Museu Nacional, Rio de Janeiro, 2000

Identidade Étnica e Recriação das Tradições entre os Migrantes de Origem Palestina no Extremo Sul do Brasil. Em: Campos - Revista de Antropologia Social. n.02: 6784. UFPR, Curitiba, 2002.

A Diáspora Palestina: As Organizações Sanaud e a Experiência Geracional Acerca da Identidade Palestina no Sul do Brasil. Em: Schiocchet, Leonardo (Org.). Entre o Velho eu Novo Mundo: A Diáspora Palestina Desde o Oriente Médio à América Latina. 1 a edição. Chiado Print, Lisboa, Portugal, Julho, 2015.

Levine, Mark: Heavy Metal Islam: Rock, Resistence, And The Struggle For The Soul Of Islam. Three Rivers Press, New York, 2008.

Lovatt, Hugh. Palestinian Hip-Hop Culture and Rap Music: Cultural Resistance as an Alternative to Armed Struggle. BA Arabic. Institute of Arabic and Islamic Studies, Exeter University, 2009.

Manfrinato, Helena de Morais. Dos quadros de guerra à participação: notas sobre a jornada do refúgio palestino em São Paulo. Cadernos de Campo (USP), v. 25, p. 421, 2017.

Mcdonald, David A.: My voice is my weapon: music, nationalism, and the poetics of Palestinian resistance. Duke University Press, 2013.

Montenegro, Silvia. La triple frontera entre Argentina, Brasil y Paraguay: globalización y construcción social del espacio. XXVI Congresso de la Asociación Latinoamericana de Sociología. Asociación Latinoamericana de Sociología, Guadalajara, 2007.

Oliveira, Luciana Garcia de. A diáspora palestina no Brasil - A FEPAL: Trajetórias, reivindicações e desdobramentos (2000 - 2012). Dissertação de Mestrado, USP, 2017.

Oliveira, Rafael Gustavo de. Al Dakhel, cartografias como experiência : reflexões a partir de um trabalho de campo na Palestina. Tese (Doutorado em Antropologia), UFPR, Curitiba, 2020.

Selah al Museka: uma etnografia das práticas e produções musicais palestinas. Dissertação de Mestrado, UFPR, Curitiba, 2015.

Resenha Schiocchet, Leonardo (Org.). Entre o Velho e o Novo Mundo: A Diáspora Palestina Desde o Oriente Médio à América Latina. 1a edição. Chiado Print, Lisboa, Portugal, Julho, 2015. Em: Al Irfan - Revista de ciencias humanas y sociales / Reseñas. No 2. 2017.

A Palestina é uma só: im/possibilidade de trânsito e experiências da cartografia a partir de músicos na Palestina. Em: Adi, Ashjan Sadique; Sahd, Fábio Bacila. (Orgs.) Oriente Médio e Palestina pesquisados a partir do Brasil: reflexões acadêmicas, marginais e críticas. Uberlândia: Navegando Publicações, 2020. 
Al Dakhel, cartografias como experiência: reflexões a partir de um trabalho de campo na Palestina. Tese (Doutorado em Antropologia) - Setor de Ciências Humanas da Universidade Federal do Paraná. Curitiba, 2020.

Prates, Daniele Regina Abilas. O fio de Ariadne: deslocamento, heterotopia e memória entre refugiados palestinos em Mogi das Cruzes, Brasil e Burj Al-Barajneh, Líbano. Dissertação de Mestrado, UFF, Niterói, 2012.

Entre monges e freiras: disputa, identidade religiosa e nacionalismo nos territórios ocupados da Palestina. In: VI Jornada de Alunos PPGA/UFF 2012, 2012, Niterói. Anais VI Jornada de Alunos PPGA/UFF 2012, 2012.

"Não quero lembrar... muito sofrimento": percursos da memória entre os refugiados palestinos no Brasil. Horizontes Antropológicos. Vol.20, n.42, pp.133-152, 2014.

Espaços Habitados, Lugares Estendidos: A Experiência Dos Refugiados Palestinos no Brasil a partir de Redes Locais e Transnacionais. Em: SCHIOCCHET, Leonardo (Org.). Entre o Velho eu Novo Mundo: A Diáspora Palestina Desde o Oriente Médio à América Latina. 1 a edição. Chiado Print, Lisboa, Portugal, Julho, 2015.

Resende, Fernando A.; Robalinho, R. Eu, na fronteira dos teus olhos - sujeitos, territórios e resistência no conflito Israel/Palestina a partir de um filme de Aviv Mograbi. Revista Eco-Pós (Online), v. 17, p. 1-13, 2014.

.; Rossignoli, Letícia . O conflito Israel/Palestina como acontecimento jornalístico: análises de narrativas do jornal Folha da Manhã (1936/1946). GALÁXIA (SÃO PAULO. ONLINE), v. De2015, p. 86-98, 2015.

Ribeiro, Zenilda Lopes. Árabes Palestinos em Barra do Garças - MT: a topofilia como realidade geográfica. XIII ENANPEGE, São Paulo, 2019.

Said, Edward W. After the Last Sky: Palestinian Lives. Columbia University Press, New York, 1999.

Schiocchet, Leonardo. Refugee Lives: Ritual and Belonging in two Palestinian Refugee Camps in Lebanon. PhD Dissertation. Graduate School of Arts and Sciences, Boston University, 2011.

Palestine; Popular Culture. In: Cultural sociology of the Middle East, Asia, and Africa: an encyclopedia. Organização: Andrea L. Stanton. SAGE Publications, Inc. California, 2012.

Palestinian Refugees: Different Generations, but One Identity.The Forced Migration and Refugee Unit . The Ibrahim Abu-Lughod Institute of International Studies Birzeit University . Birzeit, Palestine, 2013

Suspicion and the Economy of Trust among Palestinian Refugees in Lebanonn: Cambridge Anthropology 32(2), Autumn, Cambridge Anthropology. 2014. 
Por uma Antropologia Assimétrica da Palestinidade, Em: Entre o Velho eu Novo Mundo: A Diáspora Palestina Desde o Oriente Médio à América Latina. Leonardo Schiocchet (Org). 1 a edição. Chiado Print, Lisboa, Portugal, Julho, 2015.

. Uma Nação Sem Estado: A Palestina dos Palestinos in Limoncic, Flávio \& Martinho, Francisco. A Experiência Nacional, pp. 353-84. Rio de Janeiro: Editora Civilização Brasileira, 2017.

Schvarzman, Sheila. Israel: Nova história e cinema pós-sionista. Em: Significação: Revista de Cultura Audiovisual, v.40, n.40, 2013.

Stephan, C. A Burocratização da Segurança Internacional: a prolongada assistência humanitária da UNRWA aos refugiados da Palestina no Oriente Médio. CONJUNTURA GLOBAL, v. 7, p. 276296, 2018.

A UNRWA e a Assistência Humanitária Prolongada aos Refugiados Palestinos: uma análise do papel da agência no conflito árabe-israelense. Dissertação de Mestrado, UFPR, 2014 11, p. 1-7, 2018.

O Ciberativismo pelos Direitos Humanos em Israel/Palestina. MUNDORAMA, v.

Processo 'Parcialmente Imparcial': os Estados Unidos como Mediadores das Negociações de Paz entre Israel/Palestina. Conjuntura Global, v. 3, p. 184-193, 2014.

UNRWA: O Compromisso da Sociedade Internacional com os Refugiados Palestinos. Conjuntura Global, v. 1, p. 41-44, 2013.

Teles, Barbara Caramuru. "La tierra Palestina es más cara que el oro": narrativas palestinas em disputa. Dissertação de Mestrado. UFPR, Curitiba, 2017.

Da Palestina ao Chile: sobre deslocamentos e mobilidades e a construção de categorias de alteridade. Em: Adi, Ashjan Sadique; Sahd, Fábio Bacila. (Orgs.) Oriente Médio e Palestina pesquisados a partir do Brasil: reflexões acadêmicas, marginais e críticas. Uberlândia: Navegando Publicações, 2020.

. "La resistencia palestina es mujer y está furiosa". Trabalho apresentado na 32a Reunião Brasileira de Antropologia, entre 30 de outubro e 6 de setembro de 2020.

Zucchi, Luciano Kneip. Implementação do Estado de Israel e a Gênese dos Conflitos Israelo / Árabes. Tese de Doutorado. UNESP. Marília, 2020. 